ORIGINAL ARTICLE

\title{
Dental Anxiety, Smoking and Snuff Use among Dental Patients
}

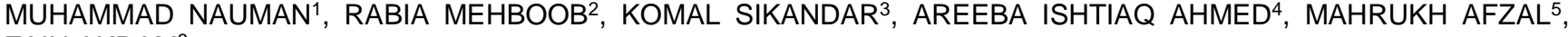 \\ ZAIN AKRAM6 \\ ${ }_{1,4}$ House Officer, Dental Department Fatima Memorial hospital, Lahore \\ ${ }^{2,3}$ House Officer, Dental Department Ibne Sina Hospital and Research Centre, Multan \\ ${ }^{5}$ Dental Surgeon, Siddique Dental Surgery, Lahore \\ ${ }^{6}$ Senior Registrar/ Consultant Oral Medicine, Fatima Memorial Hospital, Lahore \\ Corresponding author: Dr. Muhammad Nauman, Email: muhammadnauman100@gmail_com, Contact: +92 3214312862
}

\begin{abstract}
Background and Aims: Dental anxiety often causes psychological problems including the fear that have a negative impact on dental treatment. Periodontal health and dental deteriorating might be caused by the patient's interference with dental fear. The current study aims to evaluate dental anxiety, smoking and snuff use in dental patients.

Methods:One hundred eighty consecutive dental patients with meanage $\pm S D 31.45 \pm 13.75$ were investigated for dental anxiety, smoking, and snuff use.The evaluation of dental anxiety was measured with the specific question "Do youfeel any type of anxiety while visiting the dentist?" and their answers were givenas follows: "Absolutely not", "Somehow" and "Extreme fear". Tobacco use wasinvestigated with the question "Do you smoke or take snuff?" with the alternatereplies "Absolutely not", "regularly on a daily basis" and "occasionally. Chi-squaretest and multiple regression analysis were carried out in statistical analysisusing SPSS version 20.

Results:Among one hundred eighty dental patients, higher dental anxiety was reported in 32 (17.8\%) being common among women $(71.9 \%)$ than men (28.1\%). General mood and social situation was reported negative in 9 and 36 patients respectively. It was observed that tobacco use on routine a basis was more common among men $(8.5 \%)$ than women (1.5\%). Age played key a role in dental fears among patients. Patients of young age feel more anxious than mature or older aged patients. Higher dental anxiety and fear was observed in those dental patients who used snuff on a regular basis compared to occasional and no users at all while controlling for age, social status, and general mood. It was observed that chain smokers feel more anxious compared to occasional or no smoking at all, when smoking was added to the model and asked the participants about their visits to the dentists.

Conclusion: Our study findings were common vulnerability factors among dental patients related to dental anxiety or fear, smoking, and snuff use. The reason for patients' anxiety was found to be the fear of pain which was more common among women compared to men. Also, Regular tobacco users felt more anxious than occasional or no users at all. Hence, dentists should focus on anxiety alleviation among patients while treatment and follow-up call for maintenance.
\end{abstract}

Keywords: Dental anxiety, Tobacco use, Dental fear

\section{INTRODUCTION}

Psychologicalproblems to some individuals are caused by dental fear vulnerability as reportedin various studies [1-3]. People with high dental fear are more susceptible topsychological problems such as mood order, tobacco use, and anxiety complaintscompared to lower dental fear levels $[4,5]$. These problems were found in both the young and adult populations. Maintenance, recurrence, and onset of psychologicalproblems could be better understood by adopting cognitive vulnerability.Tobacco and nicotine dependence reported the risk indicators forpsychopathology $[6,7]$. Individuals might face similar problems related tosmoking and anxiety [8-12]. A high rate of anxiety was seen among young andadult patients who were smoking on regular a basis compared to no-smokers. The male population was more anxious than women [13]. Similarly, higher dental fearswere reported among snuff users compared to occasional and not at all users. Similarto smoking, psychological problems are caused by snuff usage among dentalpatients [14, 15]. Smokers had a higher proportion in terms of depression compared tononsmoker [16]. Other studies reported more anxiety in smokers than a non-smoker[17] just like dental fears [18].
Socio-economic status, age, and gender hadsignificant influence over tobacco usage and dental fear association. Womensuffer in half proportion compared to men regarding smoking disorder as foundby various consistency studies [19-21]. In addition, low socioeconomic statuspeople had a higher prevalence of smoking as shown in the study [22]. Comparingdental fear among women, young age patients, and individual education, it hasbeen found that lower educational level, women and young age patients felt moredental fear [23]. The socioeconomic status indicator was educational level. Smoking,dental fear, and smokeless tobacco users had a greater association with psychologicalproblems. But very few studies were conducted on their association. Differencesin socioeconomic status and age regarding dental fears [24], smoking [25], andsnuff users were reported in young and aged people. The current study aims to determine dentalanxiety, smoking, and snuff use in dental patients. According to our studyhypothesis, dental fear is more common among tobacco users and high dentalfear among regular chain smokers and snuff takers compared to nonusers. 


\section{MATERIALS AND METHODS}

This cross-sectional study was conducted on dental patients for dental anxiety, smoking, and snuff use in dental department Fatima Memorial hospital, Lahore during the period from December 2020 to February 2021. The consent form was taken from each individualprior to conducting the study, Ethical approval was taken from the ethical board of the institution. A questionnaire to each participant was provided with multiple choice of dental fear, regular tobacco usage, and smoking habits. One hundred eighty consecutive dental patients with mean age $\pm S D$ $31.45 \pm 13.75$ were investigated for dental anxiety, smoking, and snuff use. The evaluation of dental anxiety was measured with the specific question "Do you feel any type of anxiety while visiting the dentist?" and their answers were given as follows: "Absolutely not", "Somehow" and "Extreme fear or often". Tobacco use was investigated with the question "Do you smoke or take snuff?" with the alternate replies "Absolutely not", "regularly on a daily basis "and "occasionally.

A single question was set for dental fear assessment among dental patients. The questionwas based on their dental fear while visiting the dentist with answers provided asfollows: "not at all", somewhat, and "often". High-level fear was referred to"often" and lower level to somehow and not at all. These levels ofcategorization were done due to the severe consequences of high dental fearregarding dental health. Snuff usage and smoking regularities were measured witha question "do you smoke or use snuff" with alternate replies "often", "not at all", and occasionally. Snuff in this study referred to all types of smokelesstobacco. Six groups were made among dental patients for analysis purposes whichare $<19,20,21-25,26-30,31-40,>40$ years. Association of dentalanxiety, smoking, and snuff was measured in each age group. A common question wasasked to measure the mode in general "how is your mode?" provided with a scale-15 to +15 where positive value represents positive mode and vice versa. Socioeconomic status was measured withquestions about their feelings in social situations. The range of value -10 to +10 wasset as in alternate replies. Positive, neutral, and negative feelings were set according to their value.

Statistical Analysis: A bivariate model was used to measure the associations among dental anxiety, smoking, and snuff usage. The Chi-square test was used for statistical significance evaluation in bivariate regression. Controlling the age and gender effect, multiple regression analysis was carried out for associations among dental anxiety, smoking, and snuff usage. Tobacco usage, socioeconomic status, and general mood were added to the model along with repeated analysis. Age was considered as a continuous variable in the multiple regression model. SPSS version 20 was used for analysis and $p$-value $<0.05$ was considered as statistical significance.

\section{RESULTS}

Amongone hundred eighty dental patients, higher dental anxiety was reported in $32(17.8 \%)$ being common among women $(71.9 \%)$ than men $(28.1 \%)$. The general mood andsocial situation were reported negative in 9 and 36 patients respectively. It wasobserved that tobacco use on a routine basis was most common among men (8.5\%)than women $(1.5 \%)$. Age played a key rolein dental fears among patients. Patients of young age feel more anxious thanmature or older aged patients. Higherdental anxiety and fear were observed in those dental patients who used snuff ona regular basis compared to occasional and no users at all while controlling forage, social status, and general mood. Itwas observed that chain smokers feel more anxious compared to occasional or nosmoking at all when smoking was added to the model and asked the participantsabout their visits to the dentist. Six groups were made among dental patients foranalysis purposes which is $<19,20,21-25,26-30,31-40,>40$ years asshown in Table 1. Association of dental anxiety, smoking, and snuff was measuredin each age group.

Table 1. Age wise distribution among total (180) dental patients

\begin{tabular}{|l|l|l|}
\hline Age (years) & Frequency $\mathrm{n}$ & Percentage (\%) \\
\hline$<19$ & 17 & 9.4 \\
\hline 20 & 31 & 17.2 \\
\hline $21-25$ & 47 & 26.1 \\
\hline $26-30$ & 53 & 29.4 \\
\hline $31-40$ & 21 & 11.7 \\
\hline$>40$ & 11 & 6.1 \\
\hline
\end{tabular}

Age wise distribution

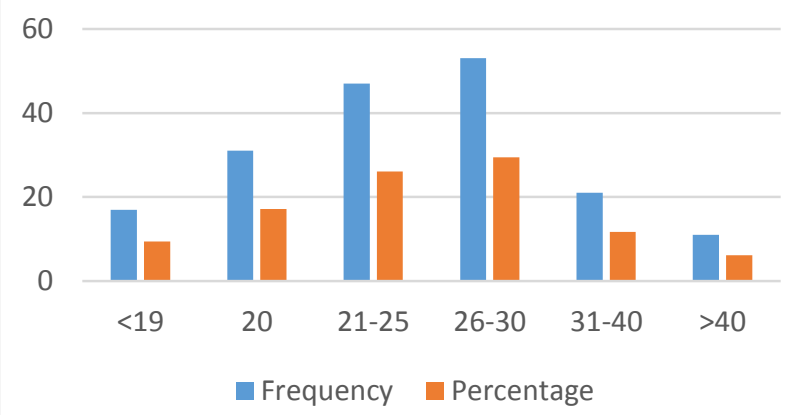

Figure 1. Age wise distribution among total (180) dental patients

Peoplewith regular tobacco users had high dental fear compared to occasional and no-users at all. In addition to the general mode, social status, gender, and tobacco usesmoking were added to the model. It was observed that chain smokers felt moreanxiety than occasional and nonusers. Dental fear hadsignificant effects on dental fear because the prevalence of dental fear wasless in positive mood than in negative mood of individuals as reported in Table2. Tobacco use was added to the model and higher dental fear were found amongregular tobacco users compared to occasional or not at all users. No associationwas found between social status feeling and dental fear according to the regressionmodel. 
Table 2. Regression analysis results

\begin{tabular}{|l|l|l|l|l|l|l|}
\hline Parameters & OR & Cl 95\% & P-value & OR & Cl 95\% & P-value \\
\hline Tobacco Use & 2.00 & $1.4-3.00$ & $<0.001$ & & & \\
\hline General mode & 1.3 & $1-2.2$ & 0.066 & 1.4 & $1-2.1$ & 0.033 \\
\hline Social situation & 1.1 & $0.9-1.5$ & 0.140 & 1.1 & $1-1.5$ & 0.105 \\
\hline
\end{tabular}

\section{DISCUSSION}

A significant association was found betweendental fear and other factors such as social status, feelings, gender, age,general mode, and tobacco use. Among regular tobacco users, high dental fear wasobserved.Generally, smoking has been associated with dental fear and anxiety [26]. High dental fear was observed in regular tobacco users compared to non-users or occasional users. The trend or proclivity of higher anxiety causes smoking and tobacco use as a self-treatment anxiolytic [27]. A significant association was found between dental fear and other factors such as social status feelings, gender, age, general mode, and tobacco use for short term anxiety may be reduced among tobacco users. However, predisposed people using tobacco had a higher proportion in development of the anxiety and dental fear over time. Anxiety may be maintained with symptoms of chronic withdrawal and emotional or somatic precipitation possibilities [28]. Interestingly, the higher prevalence of tobacco among people with harmful and hazardous smoking and snuff taking, and dental fear were observed [29]. Dental fear may be mediated by tobacco use. No clear results and their interpretation could be made because of the study's cross-sectional nature. More studies need to be conducted to know the mediating effect of tobacco for dental disorders due to other drugs.. Among regular tobacco users, high dental fear was observed.

Individuals with dental fears faced vicarious experience for treatment for controlling dental fear development than psychological fear. Likelihood of developing anxiety and smoking behaviors increases by smoking and dental fear vulnerability. Individuals having dental phobia are susceptible to these sets of factors. Psychological problems and common behavior patterns were observed among people who used smoking and taking snuff as a self-medication [30]. Smoking pathogenesis was highly dependent on genetic factors as reported by various researchers [31] and significant heritability of nicotine dependency and genetic factors affect dental fear [32]. Dental fear, smoking and tobacco use had common vulnerability influences and characterized as constitutional vulnerability [33].

Higher dental fears were observed among negative mood people compared to neutral or positive one when general mood was taken into account with gender, tobacco use, age and social status feelings. Mood disorders were measured with the nature of general mood. Our study reported that high dental fear exists among high level depressed people compared to low depressed people as found by many other researchers [34]. No association between dental fear and social status was found in our study. Social status based on performance and small group talk have shifted interaction from social status and its feeling was determined by oral presentation. Social behavior could be greatly influenced by social status variation [35]. Inadequate results were found when association between social status and dental anxiety was done. Reliable and validated data was shown among adult populations in order to measure dental phobia which is the strength of this study [36]. The limitations of our study includes small sample size and most of the young population were neglected as well as health inquiry was not responded to in half of the participants.

\section{CONCLUSION}

Our study findings were common vulnerability factors among dental patients related to dental anxiety or fear, smoking, and snuff use. The reason for patients' anxiety was found to be the fear of pain which was more common among women compared to men. Also, Regular tobacco users felt more anxious than occasional or no users at all. Hence, dentists should focus on anxiety alleviation among patients while treatment and follow-up call for maintenance.Our study found that regular tobacco users had higher dental fear than occasional or not at all users. When treating fearful patients, dentists should consider their vulnerability to dental fear, as well as their use of tobacco due to health problems caused by various risk factors. Dentists performed brief intervention for tobacco that could raise anti-smoking efforts. The dentist should assist psychologists and general practitioners in order to help people who smoke or are afraid of the dentist.

\section{REFERENCES}

1. Pohjola V, Puolakka A, Kunttu K, Virtanen JI. Association between dental fear, physical activity and physical and mental well-being among Finnish university students. ActaOdontologicaScandinavica. 2020 Jan 2;78(1):45-51.

2. Wiener RC, Findley PA, Shen C. Dental and Oral Health. InHandbook of Rural Aging 2021 Mar 24 (pp. 95-99). Routledge.

3. Vainionpää R, Pesonen $\mathrm{P}$, Laitala ML, Pohjola V, Anttonen $\checkmark$. Dental fear and dental health and attendance among Finnish male prisoners. Journal of oral \& maxillofacial research. 2019 Oct;10(4).

4. Almoznino G, Zini A, Sharav $Y$, Yanko R, Lvovsky A, Aframian DJ (2016) Overlap between dental anxiety, gagging and bloodinjection-injury related fears-a spectrum of one multidimensional phenomenon. PhysiolBehav 165:231-238. https://doi.org/10. 1016/j.physbeh.2016.07.021. S0031-9384(16)30586-8 [pii]

5. Jafer M, Crutzen R, Ibrahim A, Moafa I, Zaylaee H, Ajeely M, van den Borne B, Zanza A, Testarelli L, Patil S. Using the Exploratory Sequential Mixed Methods Design to Investigate Dental Patients' Perceptions and Needs Concerning Oral Cancer Information, Examination, Prevention and Behavior. International Journal of Environmental Research and Public Health. 2021 Jan;18(14):7562.

6. Bidyasagar SC, Marya CM, Nagpal R, Kataria S, Taneja P. Tobacco Use and Tooth Loss among Adults Residing in Faridabad, Haryana, India. Journal of Oral Health and Community Dentistry. 2019 May;13(2):51.

7. Ramôa CP, Eissenberg T, Sahingur SE. Increasing popularity of waterpipe tobacco smoking and electronic cigarette use: Implications for oral healthcare. Journal of periodontal research. 2017 Oct;52(5):813-23. 
8. Lin CS (2013) Pain catastrophizing in dental patients: implications for treatment management. J Am Dent Assoc 144(11):1244-1251

9. DI, Anamelechi J. Smoking, Teeth, \& Gums: 8 Hazards+ Best Quitting Strategies. Oral Health. 2021 Jun 15.

10. Pohjola V, Mattila AK, Joukamaa M, Lahti S: Alcohol use disorder, smoking and dental fear among adults in Finland. ActaOdontolScand 2013, 71:300-306.

11. Bhadauria US, SANDESH N, MISHRA P, GODHA S. Effect of injection site pre-cooling on pain perception in patients attending a dental camp at life line express: a split mouth interventional study. Clujul Medical. 2017;90(2):220.

12. Khanna SS, Dhaimade PA. Artificial intelligence: transforming dentistry today. Indian J Basic Appl Med Res. 2017 Jun;6(3):161-7.

13. Lasser K, Boyd JW, Woolhandler S, Himmelstein DU, McCormick D, Bor DH: Smoking and mental illness: a population-based prevalence study. JAMA 2000, 284:26062610.

14. Moylan S, Jacka FN, Pasco JA, Berk M: Cigarette smoking, nicotinedependence and anxiety disorders: a systematic review of population-based, epidemiological studies. BMC Med 2012, 10:123.

15. Routh S, BH MP, Rajesh G, Shenoy R, Sarit S. Relationship between Dental Anxiety, Oral Health Related Quality of Life and Oral Health Status of Indian Coast Guard Personnel in Mangalore, Karnataka. Indian Journal of Public Health Research \& Development. 2019 Aug 1;10(8).

16. Cranford JA, Eisenberg D, Serras AM: Substance use behaviors, mental health problems, and use of mental health services in a probability sample of college students. Addict Behav 2009, 34:134-145.

17. Schleicher HE, Harris KJ, Catley D, Nazir N: The role of depression and negative affect regulation expectancies in tobacco smoking among college students. J Am Coll Health 2009, 57:507-512

18. Merikangas KR, McClair VL: Epidemiology of substance use disorders. Hum Genet 2012, 131:779-789.

19. Kunttu K, Pesonen T: Student health survey 2012: a national survey among Finnish university students. Helsinki: Finnish Student Health Service. Reports 47, 2013. http://www.yths.fi/filebank/2263-KOTT2012_in_English.pdf (2.3.2014).

20. Schaap MM, Kunst AE: Monitoring of socio-economic inequalities in smoking: learning from the experiences of recent scientific studies. Public Health 2009, 123:103-109.

21. Mostofsky DI, Fortune F (Eds): Behavioral dentistry. 2nd edition. Ames, lowa: Wiley Blackwell; 2014

22. Sussman S, Arnett JJ: Emerging adulthood: developmental period facilitative of the addictions. Eval Health Prof 2014, 37:147-155.
23. Viinikangas $A$, Lahti $S$, Yuan $S$, Pietilä I, Freeman $R$, Humphris G: Evaluating a single dental anxiety question in Finnish adults. ActaOdontolScand 2007, 65:236-240.

24. Saunders JB, Aasland OG, Babor TF, de la Fuente JR, Grant M: Developmentof the alcohol Use disorders identification test (AUDIT): WHO collaborative project on early detection of persons with harmful alcohol consumption-II. Addiction 1993, 88:791-804.

25. Hodgson R, Alwyn T, John B, Thom B, The SA, FAST: Alcohol screening test.Alcohol Alcohol 2002, 37:61-66.

26. Björklund $\mathrm{K}$, Häkkänen-Nyholm $\mathrm{H}$, Huttunen $\mathrm{T}$, Kunttu $\mathrm{K}$ : Violencevictimization among Finnish university students: prevalence, symptomsand healthcare usage. SocSci Med 2010, 70:1416-1422.

27. IBM Corp: IBM SPSS Statistics for Windows, Version 20.0. Armonk, NY: IBM Corp; 2011.

28. McLeish AC, Zvolensky MJ, Del Ben KS, Burke RS: Anxiety sensitivity as a moderator of the association between smoking rate and panic-relevant symptoms among a community sample of middle-aged adult daily smokers. Am $\mathrm{J}$ Addict 2009, 18:93-99.

29. Kalman D, Kim S, DiGirolamo G, Smelson D, Ziedonis D: Addressing tobaccouse disorder in smokers in early remission from alcohol dependence: the case for integrating smoking cessation services in substance use disorder treatment programs. ClinPsychol Rev 2010, 30:12-24.

30. Miskulin M, Petrović G, Miskulin I, Puntarić D, Milas J, Dahl $D$, Rudan S: Prevalence and risk factors of alcohol abuse among university students from eastern Croatia: questionnaire study. CollAntropol 2010, 34:1315-1322.

31. Rachman S: Neo-conditioning and the classical theory of fear acquisition.ClinPsychol Rev 1991, 11:155-173.

32. Smith JP, Randall CL: Anxiety and alcohol Use disorders: comorbidity andtreatment considerations. Alcohol Res 2012, 34:414-431.

33. Kimura M, Higuchi S: Genetics of alcohol dependence. Psychiatry ClinNeurosci2011, 65:213-225.

34. Lessov-Schlaggar CN, Pergadia ML, Khroyan TV, Swan GE: Genetics of nicotinedependence and pharmacotherapy. BiochemPharmacol 2008, 75:178-195.

35. Delgado-Angulo EK, Sabbah W, Suominen AL, Vehkalahti MM,KnuuttilaM,PartonenT,NordbladA,SheihamA,WattRG,Ts akos $\mathrm{G}$ (2015) The association of depression and anxiety with dental caries and periodontal disease among Finnish adults. Community Dent Oral Epidemiol. https://doi.org/10.1111/cdoe.12179 34.

36. Khambaty T, Stewart JC (2013) Associations of depressive and anxiety disorders with periodontal disease prevalence in young adults: analysis of 1999-2004 National Health and Nutrition Examination Survey (NHANES) data. Ann Behav Med 45(3): 393-397. https://doi.org/10.1007/s12160-0139471-0 